\title{
Mixed-mode fracture toughness of bond lines of PRF and PUR adhesives in European beech wood
}

\section{Journal Article}

Author(s):

Ammann, Samuel; Niemz, Peter

Publication date:

2014

Permanent link:

https://doi.org/10.3929/ethz-b-000092623

Rights / license:

In Copyright - Non-Commercial Use Permitted

Originally published in:

Holzforschung 69(4), https://doi.org/10.1515/hf-2014-0096 


\section{Mixed-mode fracture toughness of bond lines of PRF and PUR adhesives in European beech wood}

\begin{abstract}
The fracture behavior of bond lines in hardwood has been studied. The joints of a phenol resorcinol formaldehyde (PRF) resin and a one-component polyurethane (PUR) adhesive with European beech wood (Fagus sylvatica L.) adherends were examined for their fracture toughness $\left(K_{c}\right)$. The initial crack tip was placed directly in the adhesive as a thin silicon film. Thereby, the examination of the bond line, and not the solid wood, can be assured. Five different load angles were applied, from fracture mode 1 (M1) to mode 2 (M2), with an Arcan test mount. Additionally, three sample series conditioned at the relative humidities (RH) of $50 \%, 65 \%$, and $95 \%$ of the surrounding air were tested. The results clearly show an increasing $K_{c}$ of both adhesives with increasing shear stresses. This observation is valid for all RHs, but the differences decrease with increasing RH. The moisture dependency is more pronounced in PUR than in PRF glue joints. PUR generally shows a lower $K_{\mathrm{c}}$ than PRF, with the only exceptions being $K_{\mathrm{I}, \mathrm{c}}$ and $K_{\mathrm{II}, \mathrm{c}}$ in dry climate. The subsequent crack propagation in the PRF samples mainly takes place in the wood adherend, whereas, in the PUR samples, the cracks remain within the bond line (adhesive failure). Nevertheless, the performance of PUR glue joints is not worse than that of the solid wood, which can be attributed to the ductile behavior of the adhesive.
\end{abstract}

Keywords: adhesive failure, European beech, fracture toughness, glue joints, mixed-mode, one-component polyurethane (PUR), phenol resorcinol formaldehyde (PRF) resin

DOI 10.1515/hf-2014-0096

Received March 27, 2014; accepted September 17, 2014; previously published online October 10, 2014

\footnotetext{
*Corresponding author: Samuel Ammann, Institute for Building Materials, Department of Civil, Environmental and Geomatic Engineering, ETH Zurich, HIF E 27, Stefano-Franscini-Platz 3, CH-8093 Zurich, Switzerland, e-mail: ammanns@ethz.ch Peter Niemz: Institute for Building Materials, Department of Civil, Environmental and Geomatic Engineering, ETH Zurich, Zurich, Switzerland
}

\section{Introduction}

Hardwoods are gaining popularity in the European timber construction industry. The common hardwoods have a good potential to either locally support softwood constructions at the zones of increased load or even replace softwood constructions by a slimmer design, on account of the higher values of their elementary parameters of strength and stiffness (Wagenführ 2007). However, due to the hygric nature of wood, higher mechanical properties also result in higher internal stresses caused by environmental changes, most notably changes in the surrounding humidity. Therefore, in timber engineering, softwoods cannot simply be replaced with hardwoods based on their superior parameters, and the purpose of the construction and its local conditions also has to be taken into account.

Nowadays, wooden structural elements are mostly glued either simply to get the desired cross-section or to achieve a certain homogeneity within a wooden element. Such glue joints are crucial for a structure's safety. Nonetheless, the processes responsible for the performance of glue joints, especially in hardwoods, are not entirely apparent and are still a topic of many scientific investigations (Yan et al. 2013). Most wood adhesives are designed for softwood and have proven their quality countless times. However, hardwood applications are rare due to the lack of knowledge and missing standards. Consequently, a better understanding of the bonding mechanics is necessary to produce reliable, adhesively bonded hardwood elements and to broaden the application of hardwoods in general.

A good approach to determine the safety of a structure would be a numerical simulation. However, the task to model the wood itself is already a considerable challenge (Hanhijärvi 1995; Ormarsson 1999; Serrano 2000; Danielsson and Gustafsson 2011; Hering 2011; Qiu et al. 2014) that must be accompanied with simplifications due to the lack of experimental data and the complexity of the material itself. Therefore, most numerical investigations focus only on one specific problem. Danielsson and Gustafsson (2011) analyzed quadratic holes in glulam elements with a probabilistic approach and achieved results close to the experimental tests. Finger joints and their modeling 
were elaborately investigated by Serrano (2000). Hanhijärvi (1995) analyzed the mechanosorptive behavior, and Ormarsson (1999) focused on the distortions induced by moisture changes. Crack propagation in solid wood was analyzed by Qiu et al. (2014). Another approach is modeling the materials themselves, not limiting to a specific application. Hering (2011), for example, developed an extensive material model [finite element method (FEM)] for beech wood and glued elements, but the work was focused only on the elastic range due to the complexity of wood and the numerous parameters.

As also stated by Danielsson and Gustafsson (2011), the application of existing standards (for softwoods) would also not deliver satisfactory results, since they are based on empirical values and their test setups are not based on realistic scenarios (EN 302-2 2013). Therefore, it is important to examine glue joints in hardwoods experimentally and from different perspectives for a reliable prediction of a structure's behavior and to guarantee its structural safety for decades.

Here, an attempt is made to study the fracture behavior of cracks within the bond lines in hardwood. To characterize the fracture behavior, the fracture toughness was measured under five different load angles [mode 1 (M1) to mode 2 (M2)]. The relative humidity (RH) was varied and two different adhesives types were observed.

\section{Materials and methods}

European beech wood (Fagus sylvatica L.) was in focus. The samples were prepared from the same trunk lumbered in the region of Zurich, Switzerland. Prior to sample preparation, the raw beech wood boards were conditioned at standard atmospheric conditions $\left(20^{\circ} \mathrm{C}\right.$, $65 \% \mathrm{RH}$ ) until the equilibrium moisture content (EMC) was reached. At that point, the wood had a density of approximately $706 \mathrm{~kg} \mathrm{~m}^{-3}$ and a MC of $14.5 \%$. After conditioning, the slats of approximately $50 \times 65 \times 400 \mathrm{~mm}^{3}$ were cut out and glued according to the manufacturers' guidelines. The investigated adhesives are as follows: (1) phenol resorcinol formaldehyde (PRF) resin Aerodux (glue $185 \mathrm{RL}$ with hardener HP 155) provided by Bolleter Composites AG (Arbon, Switzerland) and (2) one-component polyurethane (PUR) HB S 709 provided by Purbond AG (Sempach-Station, Switzerland).

Before joining the slats, thin silicon-coated films with a thickness of $35 \mu \mathrm{m}$ were inserted into the bond line for the initiation of the crack (Figure 1). This procedure was adapted from ISO 25217 (2009). After bonding, the slats were first stored again at standard atmospheric conditions for 7 days and then conditioned to the desired environmental humidity. Three sample series were conditioned. (1) Dry climate: $20^{\circ} \mathrm{C}, 50 \%$ RH, MC $11.0 \%$. (2) Standard climate: $20^{\circ} \mathrm{C}, 65 \%$ RH, MC $14.6 \%$ and (3) wet climate: $20^{\circ} \mathrm{C}, 95 \%$ RH, MC $21.1 \%$. Finally, samples of $6 \times 50 \times 130 \mathrm{~mm}^{3}$ were cut out, so that they contained an initial crack (i.e., silicon film) of approximately $25 \mathrm{~mm}$ length (see Figure 1 for the illustration). The orientation of the anatomic

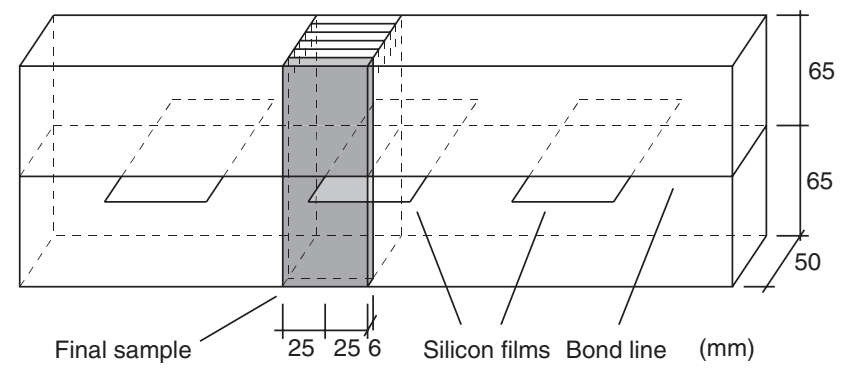

Figure 1 Sample preparation and geometry (units in $\mathrm{mm}$ ).

directions was chosen so that the crack should propagate in the longitudinal (L) direction and both latewood (LW) and earlywood (EW) are present on the crack plane, that is, with an annual ring angle of $60^{\circ}-90^{\circ}$, respective to the glue joint.

The orientation of the annual rings in the bonded samples was chosen so that they coincide with industrial bonded elements, and the crack tip was placed directly in the adhesive to assure the investigation on the adhesive, not the solid wood. Therefore, the role of the solid wood was of minor importance, and the focus clearly was on the adhesive systems. The fracture behavior of solid wood is well investigated in different anatomical directions and with different MCs. Ozyhar et al. (2012a) completed an extensive research, which included fracture mechanics, on the same source of beech wood as observed here.

The experiments were conducted on a Zwick/Roell Z010 universal testing machine with a $10 \mathrm{kN}$ load cell and an Arcan test mount (Figure 2). The Arcan test mount can be modified to realize load angles on the glue joint from $0^{\circ}$ to $90^{\circ}$ in $22.5^{\circ}$ steps. A load angle $\alpha=0^{\circ}$ therefore corresponds to the fracture mode 2 (M2), and $\alpha=90^{\circ}$ corresponds to the fracture mode 1 (M1). Mixed modes (MM) are denoted with the respective load angle as index (e.g., $\mathrm{MM}_{2.5}$ for $\alpha=22.5^{\circ}$ ). In Figure 2, an exemplary test setup for $\mathrm{M} 1\left(90^{\circ}\right)$ is shown. For greater clarity, the other load angles are also denoted in this figure.

The tests were performed with a constant displacement rate of $0.5 \mathrm{~mm} \mathrm{~min}^{-1}$ resulting in an experimental duration between 30 and $90 \mathrm{~s}$. The displacement and corresponding load were recorded during the experiments. The displacement, however, is not relevant for the

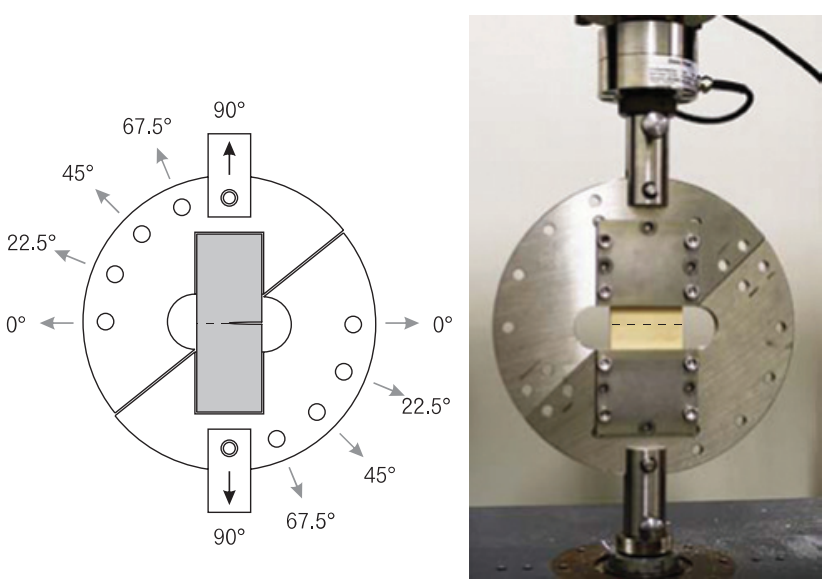

Figure 2 Arcan test with mounted sample.

The illustration on the left indicates the different load angles. The photo shows an experimental setup for M1. The dashed line indicates the glue joint. 
data evaluation [see Eqs. (1)-(3)]; therefore, the crosshead movement was taken as a measure. The exact initial crack length and sample geometry were measured straight after testing the samples.

The fracture toughness $K_{\mathrm{c}}$ was calculated using the following formulas:

$$
\begin{gathered}
K_{\mathrm{I}, \mathrm{c}}=\zeta_{\mathrm{I}}(\alpha) \cdot \frac{F_{\max }}{w \cdot t} \cdot \sqrt{\pi \cdot \alpha} \\
K_{\mathrm{II}, \mathrm{c}}=\zeta_{\mathrm{II}}(\alpha) \cdot \frac{F_{\mathrm{max}}}{w \cdot t} \cdot \sqrt{\pi \cdot \alpha} \\
K_{\alpha, c}=\sqrt{K_{\mathrm{I}, \mathrm{c}}^{2}+K_{\mathrm{II}, \mathrm{c}}^{2}}
\end{gathered}
$$

where $F_{\max }$ is the load, at which crack propagation is initiated; $w$ and $t$ are the width and thickness of the sample, respectively; $a$ is the initial crack length; and $\zeta_{\mathrm{I}}$ and $\xi_{\mathrm{II}}$ are the respective correction factors, depending on the load angle $\alpha$ (Table 1). These form factors were adapted from Richard and Benitz (1983).

After testing the samples, the wood failure percentage (WFP) was analyzed according to EN 302-1 (2013). The statistical significance was evaluated according to DIN 53804-1 (2002) with a 5\% level of significance. The standard deviations (SDs) are given for the measured values and the confidence intervals (CIs) are given for the derived results (i.e., $K_{\mathrm{c}}$ ).

\section{Results and discussion}

The above-mentioned calculation of $K_{c}$ with the corresponding correction factors is based on isotropic materials and might therefore not be valid for wood or wood-based products. However, this evaluation is still a passable approximation due to the lack of a numerical analysis (FEM) and allows the comparison of the results. For a more precise analysis (i.e., based on the FEM), all experimental results are presented in Table 2 and the actual sample geometries are listed in Table 3. The material properties for such an analysis can be found in the work of Kläusler et al. (2013) for the adhesives and Ozyhar et al. (2012a, b) for beech wood, as both materials are exactly from the same source as that studied here.

For a better overview, the $K_{c}$ values with the corresponding CIs are illustrated in Figure 3 for PUR and Figure 4 for PRF. In these figures, the monotone piecewise cubic interpolation (according to Fritsch and Carlson

Table 1 Correction factors for $M 1\left(\xi_{)}\right)$and $M 2\left(\xi_{\|}\right)$fracture toughness for different load angles $\alpha$, adapted from Richard and Benitz (1983).

\begin{tabular}{rrrrrr}
\hline & $\alpha=90^{\circ}$ & $\alpha=67.5^{\circ}$ & $\alpha=45^{\circ}$ & $\alpha=22.5^{\circ}$ & $\alpha=0^{\circ}$ \\
\hline$\zeta_{I}$ & 2.810 & 2.539 & 1.918 & 1.004 & 0 \\
$\zeta_{\text {II }}$ & 0 & 0.571 & 0.990 & 1.295 & 1.448 \\
\hline
\end{tabular}

1980) was applied to consider any local extrema, most evident at $K_{\mathrm{I}, \mathrm{c}}$ and $K_{\mathrm{II}, \mathrm{c}}$, respectively.

The bulk density of the wood lies within the common range found in the literature, being at $706 \mathrm{~kg} \mathrm{~m}^{-3}$ at standard climatic conditions. The MCs (Table 2) are slightly higher compared with literature values (Scheffler et al. 2004; Sonderegger et al. 2011; Ozyhar et al. 2012b) but are within the normal range.

No significant differences of the $K_{c}$ of the PUR glue joints can be found between load angles from M1 to $\mathrm{MM}_{22.5}$, but a significant increase is visible from $\mathrm{MM}_{22.5}$ to M2. This observation applies to all three climate steps. It can be assumed that PUR glue joints perform equally well independent of the load angle until a certain percentage of shear force is reached. In the regular to dry climates, wood failure starts to occur occasionally when decreasing the load angle to $22.5^{\circ}$. As for $K_{c}$, a distinct increase in WFP is notable between $\mathrm{MM}_{22.5}$ and M2. It thus seems plausible that, at that angle, toward pure shear load, bonding mechanisms come into account that significantly increase the glue joint's performance. The possible mechanisms can be differences in the stress field, surface roughness, and mechanical interlocking.

Similar observations can be made for the PRF in the dry and standard climates as for the PUR, except that $K_{\mathrm{I}, \mathrm{c}}$ is lower than those at the MM. However, at the wet climate, an unexpected behavior was observed. The measured $K_{\mathrm{I}, \mathrm{c}}$ of the PRF is not only higher than at standard atmosphere, but they are even at the same level as $K_{\mathrm{II}, \mathrm{c}}$ in the wet climate. The minimum $K_{c}$ can be found at a load angle of $22.5^{\circ}$ respective to the bond line, being significantly lower than $K_{\mathrm{I}, \mathrm{c}}$ and $K_{\mathrm{II}, \mathrm{c}}$. An explanation for this behavior was not found, neither in the evaluation nor in the literature.

Regarding the WFP of both adhesives (Table 2), it becomes apparent that shear stresses at glue joints promote wood failure in the system. In general, PRF predominantly produces wood failure, whereas PUR mostly fails in adhesion [Ammann and Niemz (2014) made similar observations]. However, both adhesives show increasing WFP with decreasing load angle. As already stated, the adhesive systems seem to benefit from decreasing load angles because of the better distribution of stresses at the glue joint and better physical bonding (roughness, mechanical interlocking) at the interface parallel to the joint, which is also notable in the WFP.

Despite the generally low WFP of PUR, these glue joints do not perform worse than the solid wood (Scheffler et al. 2004; Ozyhar et al. 2012b). This behavior might seem surprising at first sight, but it can be explained with the material characteristics of the adhesive. PUR, in contrast to PRF or solid wood, shows a ductile behavior 
Table 2 Material properties and results for different load angles.

\begin{tabular}{|c|c|c|c|c|c|c|}
\hline Material properties & Adhesive & $\alpha\left(^{\circ}\right)$ & $K_{\mathrm{c}} \pm \mathrm{Cl}(\mathrm{MPaVm})$ & $F_{\max } \pm \mathrm{SD}(\mathrm{N})$ & $n$ & WFP (\%) \\
\hline $50 \% \mathrm{RH}, 20^{\circ} \mathrm{C}$ & PRF & 90 & $1.34 \pm 0.25$ & $563 \pm 125$ & 8 & 85 \\
\hline$\rho_{\mathrm{b}}: 708 \pm 14 \mathrm{~kg} \mathrm{~m}^{-3}$ & & 67.5 & $1.90 \pm 0.27$ & $868 \pm 130$ & 8 & 90 \\
\hline \multirow[t]{8}{*}{ MC: $11.0 \%$} & & 45 & $1.65 \pm 0.06$ & $924 \pm 45$ & 8 & 95 \\
\hline & & 22.5 & $1.66 \pm 0.14$ & $1225 \pm 131$ & 8 & 95 \\
\hline & & 0 & $2.43 \pm 0.15$ & $2026 \pm 185$ & 8 & 90 \\
\hline & PUR & 90 & $1.07 \pm 0.11$ & $462 \pm 62$ & 8 & 0 \\
\hline & & 67.5 & $1.01 \pm 0.23$ & $461 \pm 118$ & 7 & 0 \\
\hline & & 45 & $1.08 \pm 0.10$ & $613 \pm 71$ & 8 & 0 \\
\hline & & 22.5 & $1.00 \pm 0.18$ & $736 \pm 153$ & 7 & 10 \\
\hline & & 0 & $2.21 \pm 0.37$ & $1866 \pm 257$ & 5 & 80 \\
\hline $65 \% \mathrm{RH}, 20^{\circ} \mathrm{C}$ & PRF & 90 & $1.11 \pm 0.10$ & $453 \pm 53$ & 8 & 80 \\
\hline$\rho_{\mathrm{b}}: 706 \pm 13 \mathrm{~kg} \mathrm{~m}^{-3}$ & & 67.5 & $1.62 \pm 0.27$ & $730 \pm 150$ & 8 & 90 \\
\hline \multirow[t]{8}{*}{ MC: $14.6 \%$} & & 45 & $1.42 \pm 0.15$ & $775 \pm 111$ & 8 & 95 \\
\hline & & 22.5 & $1.51 \pm 0.10$ & $1093 \pm 85$ & 8 & 100 \\
\hline & & 0 & $2.30 \pm 0.15$ & $1883 \pm 159$ & 8 & 100 \\
\hline & PUR & 90 & $0.71 \pm 0.07$ & $295 \pm 45$ & 10 & 0 \\
\hline & & 67.5 & $0.77 \pm 0.11$ & $355 \pm 73$ & 11 & 0 \\
\hline & & 45 & $0.82 \pm 0.08$ & $452 \pm 65$ & 11 & 0 \\
\hline & & 22.5 & $0.79 \pm 0.11$ & $571 \pm 106$ & 10 & 5 \\
\hline & & 0 & $1.85 \pm 0.18$ & $1524 \pm 184$ & 10 & 25 \\
\hline $95 \% \mathrm{RH}, 20^{\circ} \mathrm{C}$ & PRF & 90 & $1.70 \pm 0.13$ & $740 \pm 80$ & 8 & 90 \\
\hline$\rho_{\mathrm{b}}: 720 \pm 27 \mathrm{~kg} \mathrm{~m}^{-3}$ & & 67.5 & $1.51 \pm 0.26$ & $719 \pm 159$ & 8 & 80 \\
\hline \multirow[t]{8}{*}{ MC: $21.1 \%$} & & 45 & $1.40 \pm 0.13$ & $800 \pm 92$ & 8 & 80 \\
\hline & & 22.5 & $1.28 \pm 0.11$ & $950 \pm 100$ & 8 & 95 \\
\hline & & 0 & $1.73 \pm 0.10$ & $1463 \pm 124$ & 7 & 100 \\
\hline & PUR & 90 & $0.74 \pm 0.13$ & $317 \pm 67$ & 7 & 0 \\
\hline & & 67.5 & $0.80 \pm 0.08$ & $367 \pm 35$ & 6 & 0 \\
\hline & & 45 & $0.71 \pm 0.09$ & $407 \pm 63$ & 6 & 0 \\
\hline & & 22.5 & $0.69 \pm 0.08$ & $514 \pm 95$ & 10 & 0 \\
\hline & & 0 & $1.12 \pm 0.13$ & $942 \pm 126$ & 7 & 0 \\
\hline
\end{tabular}

$\rho_{\mathrm{b}}$, bulk density; $K_{\mathrm{c}}$, fracture toughness; $F_{\max }$, maximum load initiating crack propagation; $n$, number of specimens.

under tensile load with a distinctive plastic deformability (Kläusler et al. 2013). This characteristic allows for a better stress distribution along the glue joint and hence leads to a lower stress concentration at the crack tip (River 2003; Smith et al. 2003; Müller et al. 2005). The reduced stress concentration in the bond line also diminishes the

Table 3 Mean sample geometry and SD of the different sample groups.

\begin{tabular}{lcccr}
\hline Specimen & $\boldsymbol{n}$ & Width $(\mathrm{mm})$ & Length $(\mathrm{mm})$ & $\boldsymbol{a}_{\mathbf{0}}(\mathrm{mm})$ \\
\hline PRF & & & & \\
$50 \% \mathrm{RH}$ & 40 & $6.78 \pm 0.17$ & $49.17 \pm 0.07$ & $24.61 \pm 0.59$ \\
$65 \% \mathrm{RH}$ & 40 & $6.55 \pm 0.10$ & $49.56 \pm 0.19$ & $24.37 \pm 0.97$ \\
$95 \% \mathrm{RH}$ & 39 & $6.76 \pm 0.13$ & $49.30 \pm 0.21$ & $23.49 \pm 0.72$ \\
PUR & & & & \\
$50 \% \mathrm{RH}$ & 35 & $6.82 \pm 0.12$ & $49.09 \pm 0.22$ & $24.28 \pm 1.06$ \\
$65 \% \mathrm{RH}$ & 52 & $6.59 \pm 0.08$ & $49.49 \pm 0.26$ & $23.99 \pm 0.77$ \\
$95 \% \mathrm{RH}$ & 36 & $6.81 \pm 0.24$ & $49.40 \pm 0.10$ & $24.62 \pm 1.06$ \\
\hline
\end{tabular}

$n$, number of specimens; $a_{0}$, initial crack length. likelihood of wood failure. The fact that PUR has a higher tensile strength than beech wood perpendicular to the grain confirms that the weakest zone in PUR glue joints in beech wood is the adhesion (Ozyhar et al. 2012a; Kläusler et al. 2013; Ammann et al. 2014). However, having the superior $K_{\mathrm{I}, \mathrm{c}}$, a failure in the adhesion is preferred over wood failure, at least for M1 loads.

Both adhesive systems show generally decreasing $K_{\mathrm{c}}$ with increasing $\mathrm{RH}$. The effect is more pronounced on M2 than on the other modes. For European beech wood, Ozyhar et al. (2012a) found that, in general, all strength parameters (including $K_{\mathrm{I}, \mathrm{c}}$ ) decease with increasing $\mathrm{RH}$. Kläusler et al. (2013) found that the strength of PUR also decreases with increasing RH, but PRF is not influenced. Thereupon, it can be concluded that the decrease of $K_{c}$ of PRF glue joints is mainly attributed to the wood properties and not to the adhesive itself. With regard to PUR, a greater decrease in $K_{c}$ has to be expected when the humidity is increased. On assessing the mean values of the $K_{\mathrm{II}, \mathrm{C}}$ of PUR (Table 2), when switching from an $\mathrm{RH}$ of $50 \%$ to 


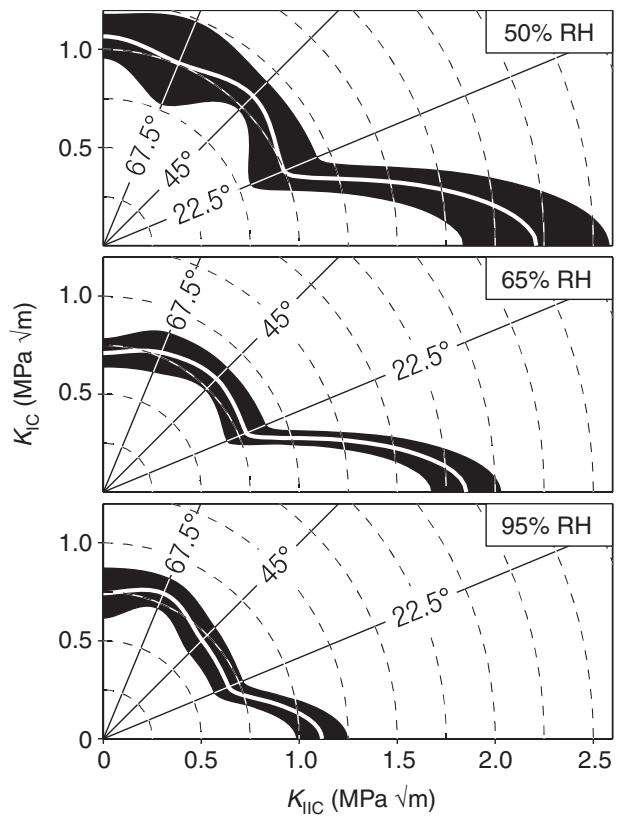

Figure $3 K_{\mathrm{c}}$ of PUR: mean with Cls (black area).

$95 \%$, one can clearly see that a factor of 2 exists, but PRF only changes by a factor of 1.5 between these values. Thus, PUR glue joints are indeed more influenced by RH than the PRF ones. However, as already stated, this effect is most notable for M2. The $K_{\mathrm{c}}$ of PUR at M1 and the MM are also lower at the standard climate than at the dry climate. However, no further changes are present between the standard and wet climates and all $K_{\mathrm{c}}$ for the mentioned load angles stay at approximately $0.75 \mathrm{MPa} / \mathrm{m}$. The $K_{\mathrm{c}}$ of PRF still decreases at the MM, when switching to wetter climates, but only at a statistically insignificant rate.

The PRF glue joints mostly perform better than those of PUR. The differences are most distinct at the MM, where PRF already has increased $K_{\mathrm{c}}$, but PUR remains at the same level of $K_{\mathrm{I}, \mathrm{c}}$. Because PUR is influenced by a different RH and PRF is not (Kläusler et al. 2013), the divergence between the performances of these adhesives increases together with the surrounding RH. Furthermore, at $50 \% \mathrm{RH}$, there are no significant differences between $K_{\mathrm{I}, \mathrm{c}}$ and $K_{\mathrm{II}, \mathrm{c}}$ of the adhesives. Therefore, if the $\mathrm{RH}$ is further decreased, one can assume that the PUR might even outperform the PRF.

\section{Conclusions}

PUR glue joints perform equally well when the applied load angle on the bond line is $>22.5^{\circ}$. At load angles

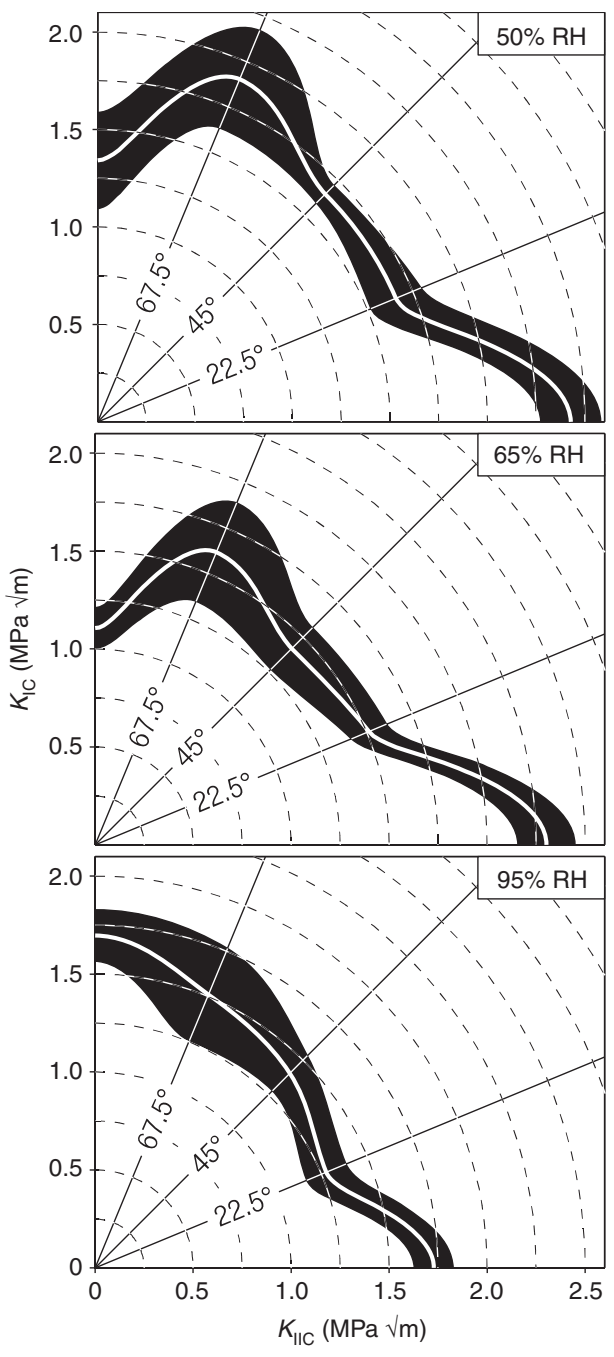

Figure $4 K_{c}$ of PRF: mean with Cls (black area).

below $22.5^{\circ}$, the $K_{\mathrm{c}}$ of PUR increases rapidly. The $K_{\mathrm{c}}$ of PRF increases with decreasing load angles. The shear stresses at glue joints promote wood failure. PRF joints mainly fail in the wood, but PUR fail in the joint itself. The weakest link of PUR glue joints in beech wood is the adhesion. Nevertheless, such glue joints do not perform worse than the solid wood. The moisture dependency is more pronounced in PUR than in PRF glue joints, which can be attributed to the adhesives' properties. At wet climates, PRF glue joints achieve higher $K_{\mathrm{c}}$ than those of PUR. However, at a moderate dry climate $(50 \% \mathrm{RH})$, there are no significant differences between PUR and PRF for $K_{\mathrm{I}, \mathrm{c}}$ and $K_{\mathrm{II}, \mathrm{c}^{\circ}}$

Acknowledgments: This research was carried out at ETH Zurich and funded through the National Research Programme (NRP 66) of the Swiss National Science Foundation. 


\section{References}

Ammann, S., Niemz, P. (2014) Fibre and adhesive bridging at glue joints in European beech wood. Wood Res.-Slovakia 59:303-312.

Ammann, S., Obersriebnig, M., Konnerth, J., Gindl-Altmutter, W., Niemz, P. (2014) Comparative adhesion analysis at glue joints in European beech and Norway spruce wood by means of nanoindentation. Int. J. Adhes. Adhes. 50:45-49.

Danielsson, H., Gustafsson, P.J. (2011) A probabilistic fracture mechanics method and strength analysis of glulam beams with holes. Eur. J. Wood Prod. 69:407-419.

DIN 53804-1 (2002) Statistical evaluation. Part 1: continuous characteristics.

EN 302-1 (2013) Adhesives for load-bearing timber structures - test methods. Part 1: determination of longitudinal tensile shear strength.

EN 302-2 (2013) Adhesives for load-bearing timber structures - test methods. Part 2: determination of resistance to delamination.

Fritsch, F., Carlson, R. (1980) Monotone piecewise cubic interpolation. SIAM J. Num. Anal. 17:238-246.

Hanhijärvi, A. (1995) Modelling of creep deformation mechanisms in wood. Ph.D. thesis, Technical Research Centre of Finland, Espoo, Finland.

Hering, S. (2011) Charakterisierung und Modellierung der Materialeigenschaften von Rotbuchenholz zur Simulation von Holzverklebungen. Ph.D. thesis, ETH Zürich, Switzerland.

ISO 25217 (2009) Adhesives - determination of the mode 1 adhesive fracture energy of structural adhesive joints using double cantilever beam and tapered double cantilever beam specimens.

Kläusler, O., Clauß, S., Lübke, L., Trachsel, J., Niemz, P. (2013) Influence of moisture on stress-strain behaviour of adhesives used for structural bonding of wood. Int. J. Adhes. Adhes. 44:57-65.

Müller, U., Sretenovic, A., Vincenti, A., Gindl, W. (2005) Direct measurement of strain distribution along a wood bond line. Part 1: shear strain concentration in a lap joint specimen by means of electronic speckle pattern interferometry. Holzforschung 59:300-306.

Ormarsson, S. (1999) Numerical analysis of moisture-related distortions in sawn timber. Ph.D. thesis, Chalmers University of Technology, Göteborg, Sweden.

Ozyhar, T., Hering, S., Niemz, P. (2012a) Moisture-dependent elastic and strength anisotropy of European beech wood in tension. J. Mater. Sci. 47:6141-6150.

Ozyhar, T., Jüstrich, S., Niemz, P. (2012b) Tensile, compressive and bending properties of European beech wood at high moisture levels. Ann. WULS-SGGW For. Wood Technol. 79:135-142.

Qiu, L.P., Zhu, E.C., van de Kuilen, J.W.G. (2014) Modeling crack propagation in wood by extended finite element method. Eur. J. Wood Prod. 72:273-283.

Richard, H.A., Benitz, K. (1983) A loading device for the creation of mixed mode in fracture mechanics. Int. J. Fract. 22:R55-R58.

River, B.H. (2003) Fracture of adhesive-bonded wood joints. In: Handbook of Adhesive Technology. Eds. Pizzi, A., Mittal, K.L., Marcel Dekker, New York. pp. 327-352.

Scheffler, M., Niemz, P., Diener, M., Lustig, V., Hardtke, H.-J. (2004) Untersuchungen zur Ermittlung der Bruchzähigkeit an Laubholz in den Rissöffnungsmodi I und II. Eur. J. Wood Prod. 62:93-100.

Serrano, E. (2000) Adhesive joints in timber engineering. Modelling and testing of fracture properties. Ph.D. thesis, Lund University, Sweden.

Smith, I., Landis, E., Gong, M. Fracture and Fatigue in Wood. Wiley \& Sons, Chichester, 2003.

Sonderegger, W., Hering, S., Niemz, P. (2011) Thermal behaviour of Norway spruce and European beech in and between the principal anatomical directions. Holzforschung 65:369-375.

Wagenführ, R. Holzatlas. 6th ed. Fachbuchverlag, Leipzig, 2007.

Yan, N., Frihart, C., Hunt, C., Eds. (2013) Proceedings of the International Conference on Wood Adhesives, Toronto, Ontario, Canada. 